\section{Materials Technologies: Goals, Strategies, and Top Accomplishments}

Advanced materials are essential for boosting the fuel economy of modern automobiles while maintaining safety and performance. Replacing cast iron and traditional steel components with lightweight materials such as high-strength steel, magnesium, aluminum, and polymer composites allows cars to carry advanced emissions-control equipment, safety devices, and integrated electronic systems without an associated weight penalty. Using lighter materials also reduces a vehicle's fuel consumption, because it takes less energy to accelerate a lighter object. For example, a 10\% reduction in vehicle weight can result in a $6 \%-8 \%$ fuel-economy improvement.

The next generation of lightweight materials - such as magnesium and carbon-fiber composites - could reduce vehicle weight by $50 \%$ while maintaining safety and performance. Lightweight materials are especially important for improving the efficiency and range of hybrid electric, plug-in hybrid electric, and electric vehicles because they offset the weight of power systems such as batteries and electric motors.

Advanced materials also increase efficiency by enabling engine components to withstand the high pressures and temperatures of high-efficiency combustion regimes. Finally, replacing the expensive materials used in electric motors and other drivetrain components with advanced materials is an important way to reduce the cost of electric-drive vehicles.

The Materials Technologies subprogram of the U.S. Department of Energy's Vehicle Technologies Program (VTP) is leading the development of high-performance, cost-effective materials - and the processes needed to manufacture themto make advanced vehicles more efficient and affordable. The subprogram's goals, strategies, and major accomplishments are described below.

\section{Goals}

More than 240 million U.S. cars and trucks consume in excess of 170 billion gallons of fuel each year. Using lightweight components and high-efficiency engines in one quarter of the U.S. fleet could save more than 5 billion gallons of fuel annually by 2030 . The Materials Technologies subprogram's goals focus on the research and development (R\&D) required to achieve this fuel savings. For passenger vehicles, the goal is to validate a cost-effective weight reduction of $50 \%$ in body and chassis systems by 2015 while maintaining safety, performance, and reliability comparable to 2002 vehicles. For commercial vehicles, the goal is to develop the materials needed to improve heavy-duty engine efficiency to $55 \%$ by 2012 while meeting U.S. Environmental Protection Agency (EPA) emissions standards.

\section{Strategies}

To achieve its materials technologies goals, VTP covers the entire R\&D spectrum, from basic sciences to demonstration and commercialization projects. In collaboration with universities, national laboratories, and the

\section{Goals}

- By 2012, develop materials to improve the efficiency of EPAcompliant heavy-duty engines to $55 \%$.

- By 2015, demonstrate a costeffective $50 \%$ weight reduction in passenger-vehicle body and chassis systems.
Conventional Steel

$\mathrm{Hi} /$ Med-Strength Steel

Polymer/Composite

Aluminum Magnesium Other

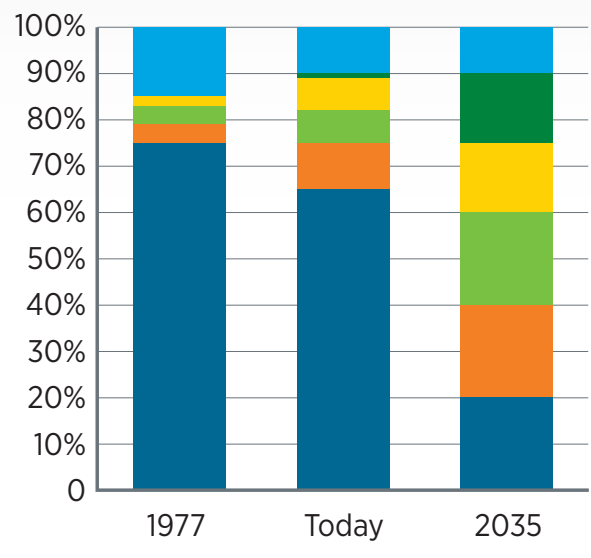

Typical composition of past and present cars versus a future lightweight vehicle.

automotive industry, this R\&D focuses on two complementary strategies:

1) "Lightweighting" (reducing the weight of) body and chassis components through use of advanced materials

2) Developing advanced engine and powertrain materials that enable more efficient propulsion systems

In the short term, lightweighting can be achieved by replacing heavy steel components with materials such as high-strength steel, aluminum, or fiberreinforced polymer composites. The properties and manufacturing of these materials are well established, but better and more cost-effective technologies and processes are needed for joining, modeling, and recycling them. In the longer term, even greater lightweighting is possible $(50 \%-75 \%$ weight reduction for some components) through use of advanced materials such as magnesium and carbon-fiber-reinforced composites. However, more extensive R\&D is needed to better understand the properties of these materials and reduce their costs. 
Chevy Malibu Maxx with a lightweight aluminum rear lift gate made by Quick Plastic Forming. Courtesy of Wieck Media Serivces

In particular, VTP is supporting R\&D that enables the development and validation of low-cost, high-performance carbonfiber composites and the manufacture and recycling of low-cost magnesium and high-performance magnesium alloys. As part of this effort, a prototype manufacturing facility for carbon fiber was created with $\$ 34.7$ million from the American Recovery and Reinvestment Act of 2009 (ARRA). This facility will validate the low-cost manufacturing of carbon fiber using innovative manufacturing processes and low-cost source materials.

Propulsion systems can be made more efficient through use of high-efficiency engines, alternative fuels, and electricdrive technologies. Each of these approaches requires materials that can maintain high performance under extreme conditions, including high temperature, pressure, and corrosiveness. VTP's Materials Technologies subprogram is developing advanced materials that can withstand these hostile conditions.

Weight Comparison of Components Built with Standard Versus Advanced Lightweight Materials

\begin{tabular}{|l|c|c|}
\hline & \multicolumn{2}{|c|}{ Weight (lb) } \\
\hline Component & $\begin{array}{c}\text { Standard } \\
\text { materials }\end{array}$ & $\begin{array}{c}\text { Advanced } \\
\text { lightweight } \\
\text { materials }\end{array}$ \\
\hline $\begin{array}{l}\text { Body-in- } \\
\text { white }\end{array}$ & 1,630 & 860 \\
\hline Body panels & 986 & 540 \\
\hline Bumpers & 137 & 97 \\
\hline $\begin{array}{l}\text { Engine } \\
\text { cradle }\end{array}$ & 77 & 31 \\
\hline $\begin{array}{l}\text { Corner } \\
\text { suspension }\end{array}$ & 104 & 57 \\
\hline Wheels & 157 & 130 \\
\hline
\end{tabular}



\section{Top Accomplishments}

\section{Developed Breakthrough Aluminum-Component Production Process}

Vehicle weight can be reduced by replacing steel with aluminum in complex components such as trunk lids or door inners, but the ability to form complex shapes from aluminum historically has been limited. This changed when VTP collaborated with General Motors (GM) and Kaiser Aluminum to develop what would become GM's "Quick Plastic Forming" process for manufacturing door components, lift gates, and various other components. GM's use of this process to replace steel with aluminum components has produced weight reductions of $35 \%$ for individual components.

\section{Commercialized Magnesium Components that Are 60\% Lighter than Steel}

Replacing steel or aluminum chassis components - such as the engine cradle and suspension - with magnesium alloys could reduce their weight by $50 \%$. However, additional R\&D is needed to bring the magnesium-casting process to full commercialization. A joint project between VTP and U.S. automakers overcame several barriers to the introduction of lightweight magnesium components. The combination of university and national laboratory R\&D and automaker expertise resulted in a magnesium engine cradle for the Chevy Corvette Z06 that is nearly $60 \%$ lighter than a steel cradle and 35\% lighter than an aluminum cradle. The project also demonstrated that magnesium components could replace steel components, even

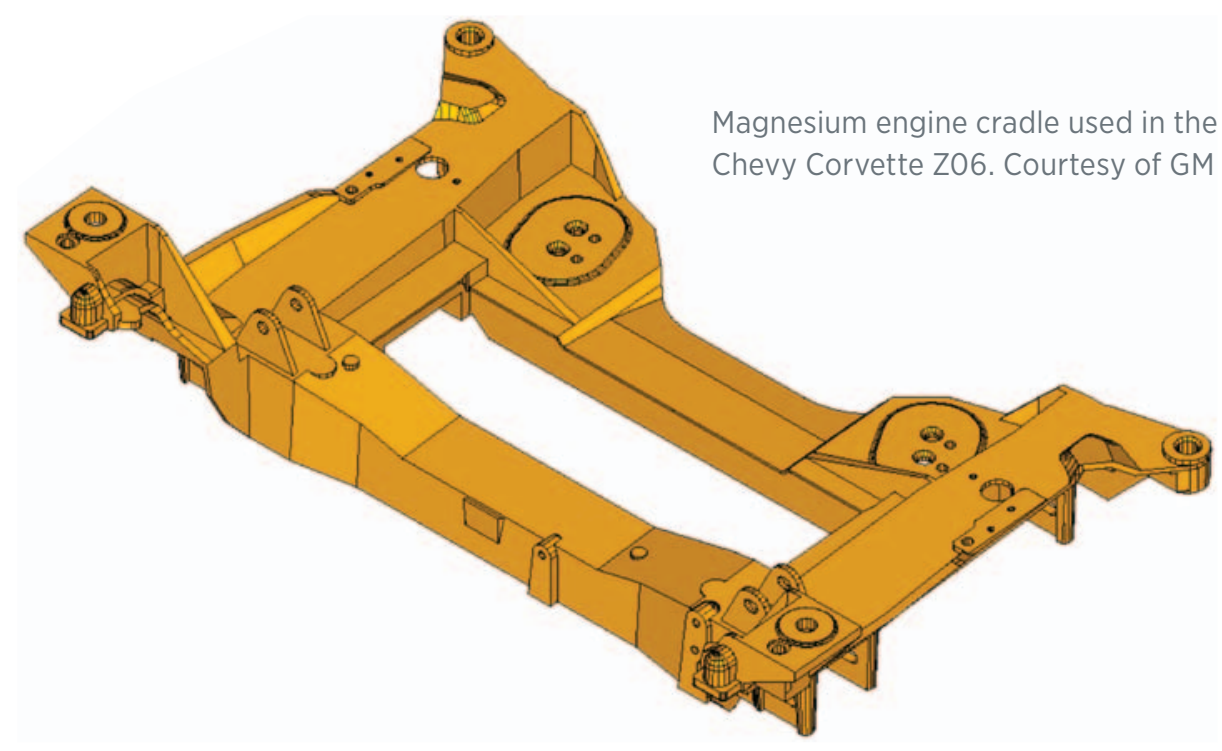




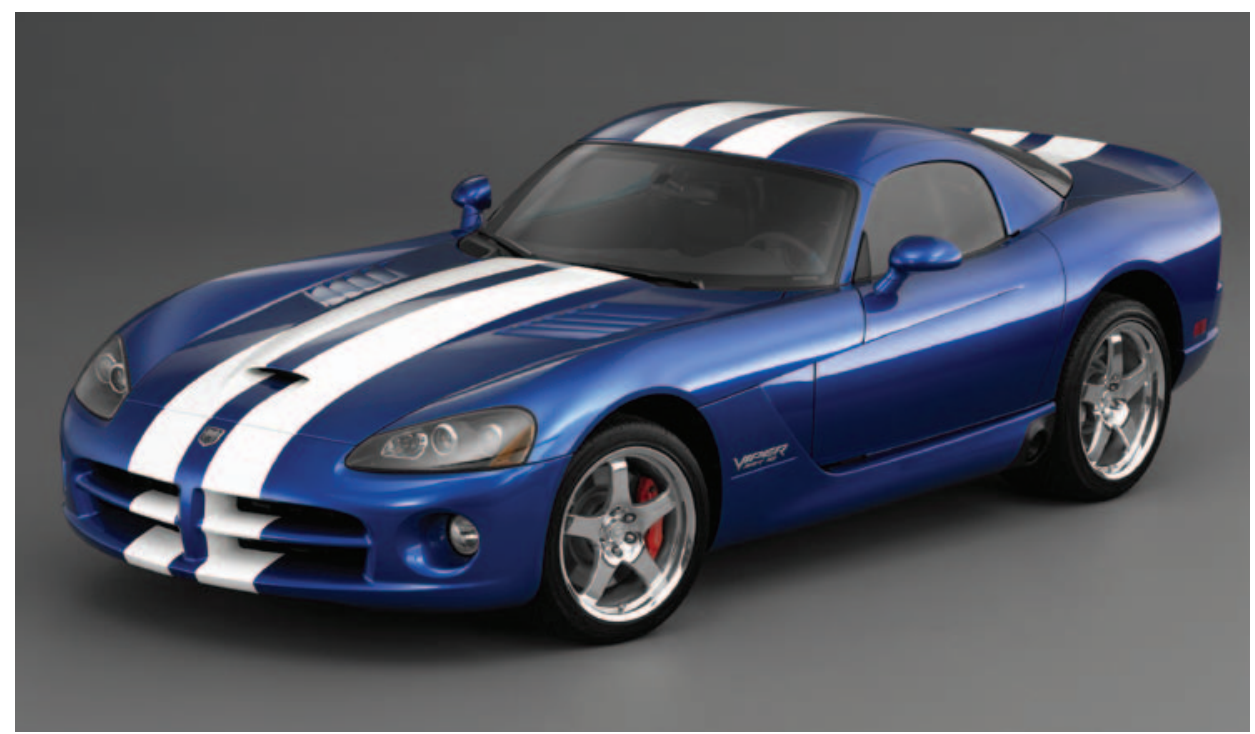

when exposed to the elements and engine heat. In addition, use of the cradle in a production vehicle initiated a magnesiumcomponent supplier base, which has since enabled the use of magnesium components in Ford cars as well.

\section{Spurred Progress in Low-Cost Carbon-Fiber Manufacturing}

Making vehicle components from carbonfiber composites can reduce vehicle weight while maintaining or improving safety. Although used in high-performance vehicles such as the Chevy Corvette Z06, Ford GT, and Dodge Viper, the high cost of carbon-fiber composites has prevented their use in more popular models. Recent VTP- supported R\&D at Oak Ridge National Laboratory holds potential to produce low-cost carbon-fiber composites that are more than 50\% lighter than conventional steel and maintain or improve strength, stiffness, and safety. In addition, ARRA funds are building a prototype facility to validate manufacturing of experimentalgrade, low-cost carbon fiber that is strong enough for vehicular applications.

\section{Developed Automotive Plastics Recycling Technology}

Shredders recover more than $95 \%$ of the metals from scrapped vehicles, but 5 million tons of plastic and non-metal materials are shipped to U.S. landfills
The 2006 Dodge Viper with carbon-fiber composite components. Courtesy of Wieck Media Services.

every year. With VTP support, Argonne National Laboratory (ANL) developed a technology that can separate many types of plastics from automotive scrapwhich typically is composed of $25 \%-40 \%$ recoverable plastics. This reduces the amount of non-biodegradable plastic sent to landfills and would save the equivalent of 24 million barrels of oil per year if widely implemented. When the technology is brought to commercialization, it is expected to yield plastic feedstock that is half the price of virgin material, creating an economic incentive for using the technology. ANL built a 2-ton-per-hour pilot plant to determine operating conditions and economics and is working with a shredder firm to develop a 20 -ton-perhour pilot plant.

\section{Optimized Aluminum-Component Design Process}

Components made from iron and steel castings have been used since the early days of automobile manufacturing, creating a large knowledge base for designers to draw on when developing new iron and steel components. Light metals such as aluminum have not been used as extensively in automotive applications. To improve the understanding of

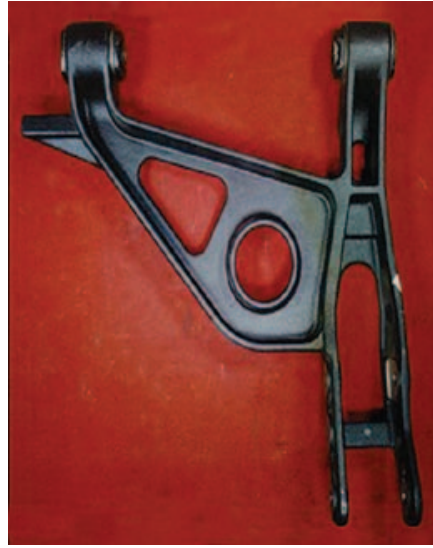

Original Design - Iron $16 \mathrm{lb}$

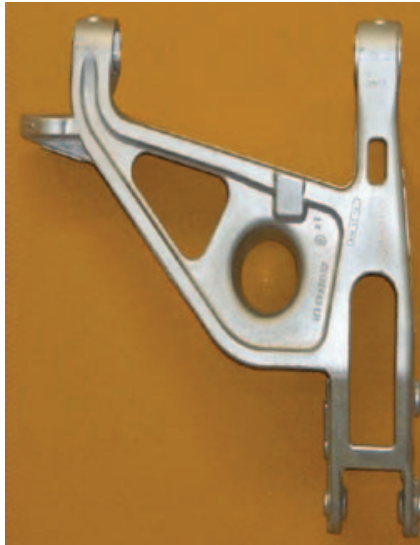

Original Design - Aluminum $6.7 \mathrm{lb}$

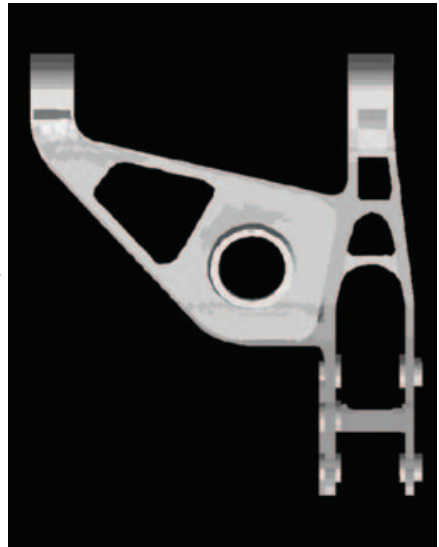

Optimized Design - Aluminum $5.4 \mathrm{lb}$ 
aluminum-casting properties and design techniques, national laboratories, universities, and U.S. automakers participated in a VTP-sponsored project to replace a steel suspension component with a castaluminum one. In the first iteration, the aluminum component was 58\% lighter than the steel component but cost more to manufacture. Further optimization of the aluminum component's design resulted in a $66 \%$ total weight reduction and no cost increase, demonstrating that designs optimized specifically for light metals could yield lower-weight and cost-neutral components. In combination with other research efforts, this project helped drive an increase in the use of cast-aluminum components in passenger vehicles. Nationwide, the proportion of an average automobile's weight made up of iron-based structural components fell from $11 \%$ in 2000 to $8 \%$ in 2007 , with a corresponding increase in the proportion of weight from aluminum components.

\section{Developed Materials Required for Clean Diesel Engines}

Research in VTP's Fuel Technologies subprogram led to the commercial introduction of ultra-low sulfur diesel fuel (ULSD) in 2006. ULSD enables use of the advanced emissions aftertreatment devices that make high-efficiency "clean diesel" vehicles so clean. However, ULSD's reduced lubricity creates reliability concerns for some fuel-system components. To address these concerns, VTP coordinated development of zirconia ceramic fuel injectors, which resist the wear ULSD causes on injectors made of traditional materials. Close cooperation between Oak Ridge National Laboratory, engine manufacturer Cummins, and ceramic suppliers resulted in improved zirconia ceramics. Cummins subsequently introduced zirconia-based timing, metering, and pumping plungers in its mid-range diesel engines.

\section{Building Tomorrow's Vehicles}

VTP's advanced materials R\&D has produced technologies that make today's vehicles more efficient, safe, and affordable. In collaboration with industry, universities, and national laboratories, VTP continues to develop the next generation of lightweight components and

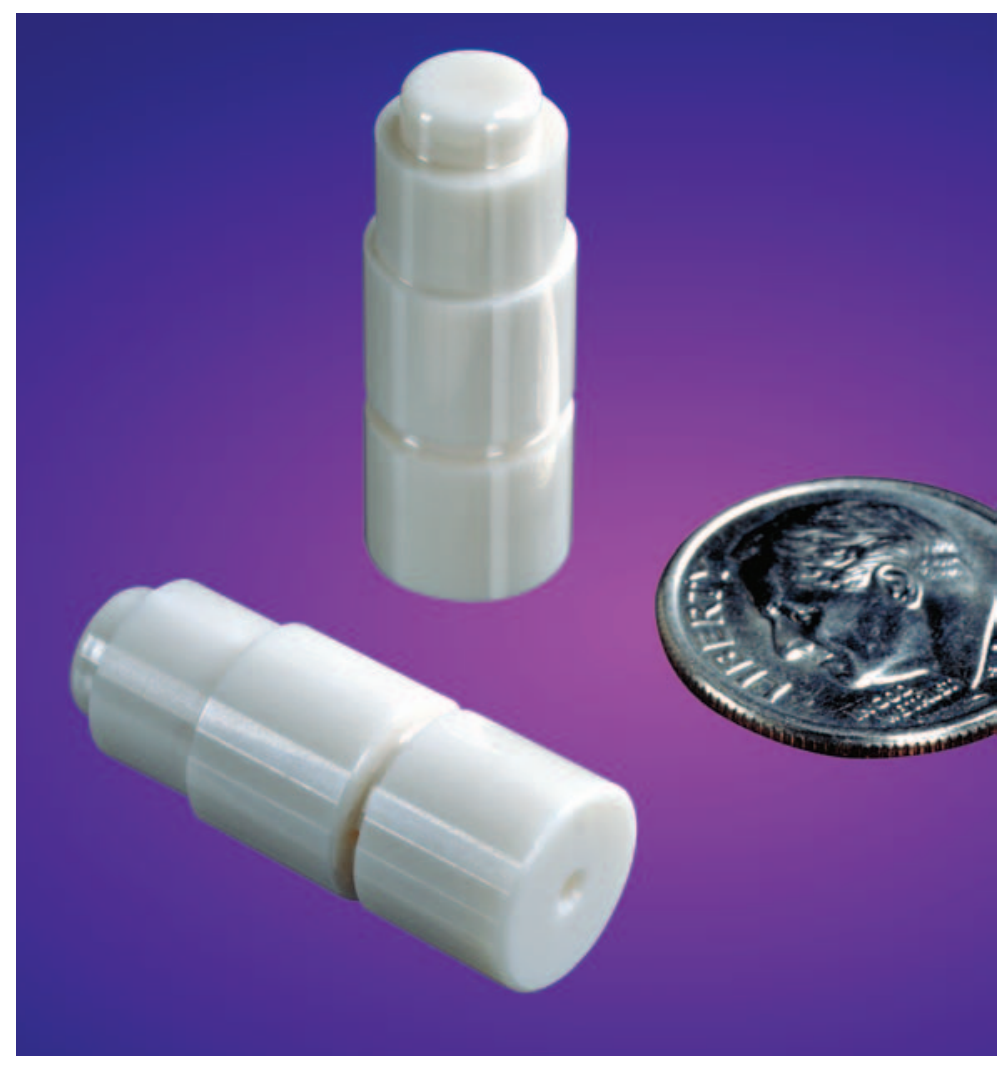

Zirconia fuel injectors. Courtesy of Cummins advanced engine and powertrain materials. These efforts are building the foundation of technologies - and technology manufacturers - that tomorrow's vehicles need to achieve ultra-high efficiency and resulting reductions in petroleum use and greenhouse gas emissions.

\section{More Information}

For more information about the Materials Technologies subprogram, contact Carol Schutte at carol. schutte@ee.doe.gov.

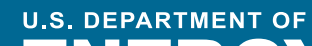
ENAROY

Energy Efficiency \& Renewable Energy
Printed with a renewable-source ink on paper containing at least $50 \%$ wastepaper, including $10 \%$ post consumer waste.
Prepared by the National Renewable Energy Laboratory (NREL) NREL is a national laboratory of the U.S. Department of Energy Office of Energy Efficiency and Renewable Energy Operated by the Alliance for Sustainable Energy, LLC

DOE/GO-102010-3111 • August 2010 